Article

\title{
Rapid and Efficient Separation of Decursin and Decursinol Angelate from Angelica gigas Nakai using Ionic Liquid, (BMIm) BF 4 , Combined with Crystallization
}

\author{
Alice Nguvoko Kiyonga ${ }^{1,+}$, Ji-Hun An ${ }^{1,+} \oplus$, Ki Yong Lee ${ }^{2,+}$, Changjin Lim ${ }^{1}$, Young-Ger Suh ${ }^{1}$, \\ Young-Won Chin ${ }^{3, *}$ and Kiwon Jung ${ }^{1, *(D)}$ \\ 1 College of Pharmacy, CHA University, Sungnam 13844, Korea \\ 2 College of Pharmacy, Korea University, Sejong City 30019, Korea \\ 3 College of Pharmacy, Dongguk University Seoul, Goyang-si, Gyeonggi-do 10326, Korea \\ * Correspondences: f2744@dongguk.edu (Y.-W.C.); pharmj@cha.ac.kr (K.J.); Tel.: +82-31-9615218 (Y.-W.C.); \\ $+82-31-8817173$ (K.J.) \\ + These authors contributed equally to this work.
}

Academic Editors: Maria Lisa Clodoveo and Filomena Corbo

Received: 29 May 2019; Accepted: 26 June 2019; Published: 28 June 2019

\begin{abstract}
Ionic liquids (ILs) have gained much attention as alternative solvents to volatile organic solvents due to their attractive properties. This study aimed to develop an efficient method for the selective separation of decursin (D) and decursinol angelate (DA) from Angelica gigas Nakai (A. gigas) using ILs and crystallization. The IL 1-butyl-3-methylimidazolium tetrafluoroborate $\left((\mathrm{BMIm}) \mathrm{BF}_{4}\right)$ was the most efficient at extracting D and DA. Parameters including solid-to-liquid ratio, time, and temperature were optimized by response surface methodology (RSM). Under optimal extraction conditions ( $1 \mathrm{~g} / 6.5 \mathrm{~mL}$ solid-to-liquid ratio, $60{ }^{\circ} \mathrm{C}$ temperature, and $120 \mathrm{~min}$ time), the extraction yields of D and DA were $43.32 \mathrm{mg} / \mathrm{g}(97.06 \%)$ and $17.87 \mathrm{mg} / \mathrm{g}(97.12 \%)$, respectively. Moreover, drowning out crystallization using deionized water (DW) as an anti-solvent offered an excellent ability to recover $\mathrm{D}$ and $\mathrm{DA}$ from the A. gigas-(BMIm) $\mathrm{BF}_{4}$ extraction solution. The rates of recovery and the total purity of D and DA were found to be greater than $97 \%$. Therefore, a rapid and efficient method of combining ILs with crystallization was effectively achieved for the selective separation of $\mathrm{D}$ and DA. This approach is assumed to be beneficial in the pharmaceutical industry for the effective obtention of D- and DA-enriched products.
\end{abstract}

Keywords: ionic liquids; decursin; decursinol angelate; Angelica gigas Nakai; crystallization

\section{Introduction}

Angelica gigas Nakai (A. gigas) is a Korean medicinal herb for which the dried roots have been extensively used in the Korean pharmacopoeia for the treatment of several diseases such as neuralgia, headache, cold, arthralgia, gynecological disorders, etc. The pyranocumarins, decursin (D) (Figure 1a) and decursinol angelate (DA) (Figure 1b) are reported as the principal bioactive compounds of this plant [1-3].

Recent studies have reported that D and DA exhibit significant effects on colon cancer [4], breast cancer [5], Alzheimer's disease [6], etc. [7-9]. Hence, studies have been intensively carried out to investigate the potential effects of D and DA on various diseases. Moreover, various techniques for the separation of D and DA, including microwave-assisted extraction [10], accelerated solvent extraction [11], etc. [12-15] have been reported as well. However, most of methods developed for the separation of D and DA are time consuming, tedious, labor-intensive, and involve repetitive 
steps, and thus, require a high consumption of volatile organic solvents. Therefore, in recent decades, studies have been conducted to remedy the shortcomings of conventional method employed for D and DA separation. Nevertheless, studies involving the development of an industrially suitable and efficient method for the selective separation of D and DA have yet not been reported. Therefore, the development of a novel approach able to improve the extraction yield, recovery, as well as the purity of D and DA is urgently needed.

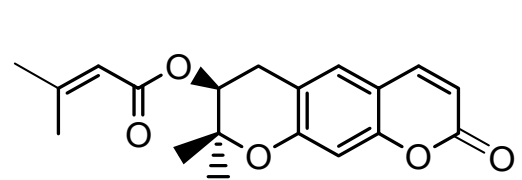

(a)

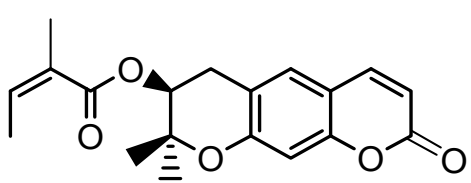

(b)

Figure 1. Chemical structures of: (a) decursin (D) and (b) decursinol angelate (DA).

In the past few decades, ionic liquids (ILs) have received considerable attention as alternative solvents to volatile organic solvents for the extraction and isolation of natural bioactive compounds. Ionic liquids is a term that refers to salts with a melting point below $100{ }^{\circ} \mathrm{C}$ and which are entirely composed of ions [16,17]. Ionic liquids possess unique and attractive properties including high selectivity, negligible vapor pressure, low volatility and inflammability, large liquid range, great chemical and thermal stability, strong solubility power and possible tunability by varying the IL's cation and anion [18,19]. In regards to their unique properties, various studies involving the applicability of ILs as solvents for the separation of phenolic compounds [20], alkaloids [21], ginsenosides [22], and other phytochemicals [23-28] have been conducted. However, due to their exceptional synthesis process, their expensive unit price, and their innumerable kinds, over $10^{18}$, studies related to the applicability of ILs in the isolation of natural products are yet insignificant.

Besides, separation techniques using supercritical carbon dioxide [29], pervaporation [30], microporous resins [31], liquid-liquid extraction [32-34], as well as crystallization [35,36] methods have been successfully applied in combination with ILs for the recovery of target compounds from the IL extraction solutions. Crystallization is an excellent separation technique because it can efficiently and easily produce single purified compounds. It is also crucial to improve the quality of obtained products [37-40]. In 2006, Lapkin et al. investigated the isolation of artemisinin, a malaria drug, using ILs as solvent and utilizing crystallization techniques. Herein, artemisinin was obtained with a high purity of $95 \%$ and the yield increased up to $82 \%$ [36].

Therefore, the present study was carried out to develop a suitable and effective method for the selective separation of D and DA from A. gigas using ILs as extraction solvent. The objective of this study was to confirm the potentiality and importance of ILs as new alternative solvents for the separation of natural compounds as well. The extraction time, temperature, and solid-to-liquid ratio were the parameters taken into consideration. Response surface methodology (RSM) with a Box-Behnken design was applied to investigate the interaction between the above parameters and to determine their influence on the extraction yields of D and DA. Further, drowning out crystallization was applied to recover D and DA from the A. gigas-IL extraction solutions using different anti-solvents. To our knowledge this was the first time a method combining ILs and crystallization has been systematically investigated and successfully achieved for the separation of D and DA from A. gigas.

\section{Results and Discussion}

\subsection{Screening of ILs}

Because of their unique and attractive properties, ILs have been efficiently applied in the separation of several bioactive compounds from plant materials. Moreover, previous studies have suggested that parameters including the structures of ILs, the cations, and/or anions of ILs influence the extraction efficiency of specific compounds [25,26]. In their study, Han et al. [20], suggested that the cation and 
anion have a large influence on the extraction efficiency of phenolic compounds from Laminaria japonica Aresch. In this regard, three ILs containing 1-butyl-3-methylimidazolium as cation and $\mathrm{Tf}_{2} \mathrm{~N}^{-}, \mathrm{PF}_{6}{ }^{-}$, and $\mathrm{BF}_{4}{ }^{-}$as anions were evaluated to examine the effect of these anions on the simultaneous extraction of $\mathrm{D}$ and DA. The extraction experiment was performed by stirring $1 \mathrm{~g}$ of dried and powdered roots of $A$. gigas with a known volume $(6 \mathrm{~mL})$ of ILs at room temperature $\left(20^{\circ} \mathrm{C}\right)$ and $500 \mathrm{rpm}$ for $2 \mathrm{~h}$. Afterwards, the extracts were filtered and then analyzed via HPLC according to the HPLC method depicted in Section 3.2. The chromatographic peaks of D and DA in the A. gigas-IL extraction solutions were confirmed by comparing their retention times and UV spectra with those of the reference standards in Figure 2.

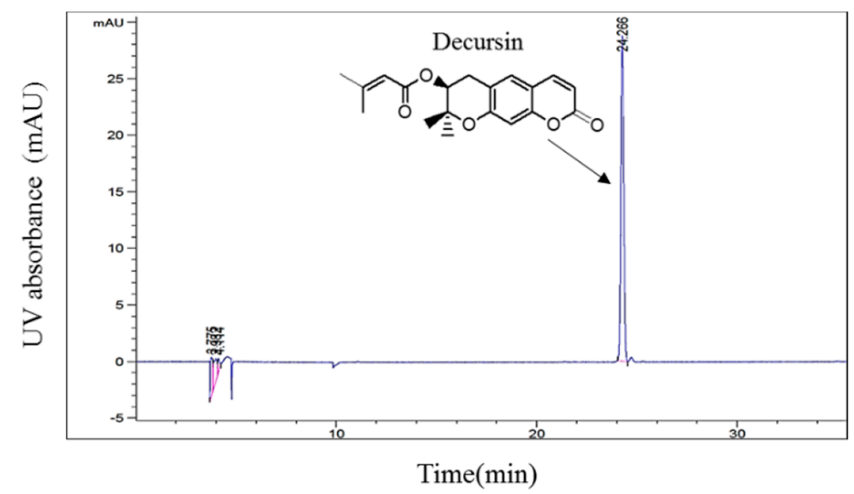

(a)

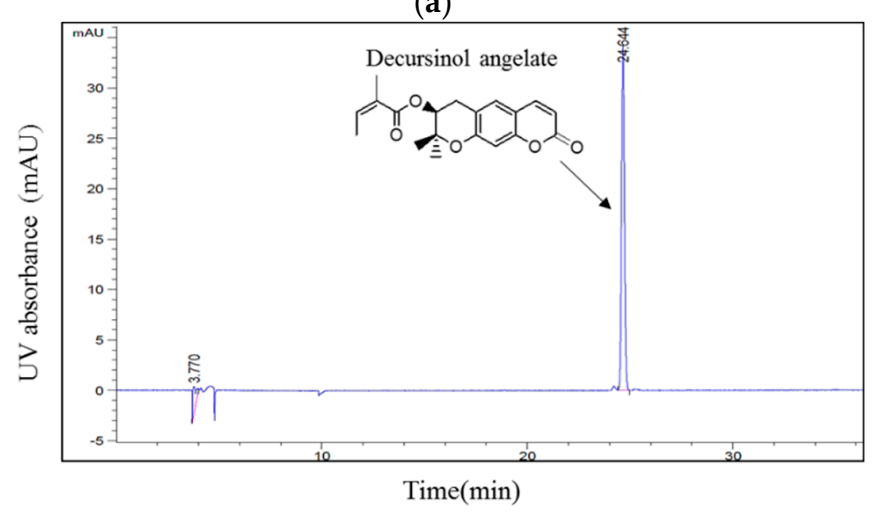

(b)

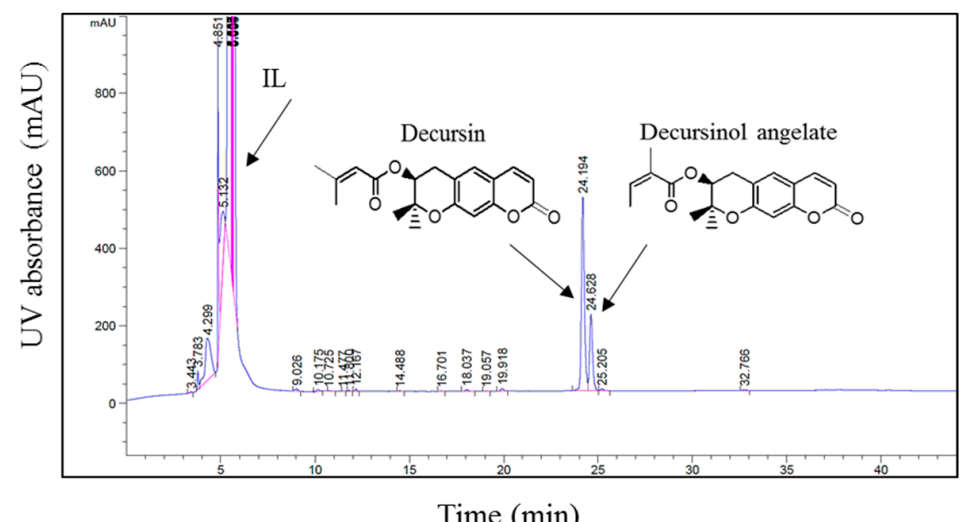

(c)

Figure 2. HPLC chromatograms of (a) D standard, (b) DA standard, (c) A. gigas-ionic liquid (IL) extraction solution. (UV $210 \mathrm{~nm}$ ). 
As can be observed in Figure $3 \mathrm{a},(\mathrm{BMIm}) \mathrm{BF}_{4}$ revealed the highest extraction capacity for both $\mathrm{D}(\mathrm{D}=40.12 \mathrm{mg} / \mathrm{g})$ and DA (DA $=15.27 \mathrm{mg} / \mathrm{g})$, followed by $(\mathrm{BMIm}) \mathrm{Tf}_{2} \mathrm{~N}(\mathrm{D}=35.00 \mathrm{mg} / \mathrm{g}$ and $\mathrm{DA}=13.90 \mathrm{mg} / \mathrm{g})$ and $\left(\mathrm{BMIm} \mathrm{PF}_{6}(\mathrm{D}=26.10 \mathrm{mg} / \mathrm{g}\right.$ and $\mathrm{DA}=11.06 \mathrm{mg} / \mathrm{g})$, respectively. Because, $(\mathrm{BMIm}) \mathrm{BF}_{4}$ and $(\mathrm{BMIm}) \mathrm{Tf}_{2} \mathrm{~N}$ demonstrated better extraction efficiencies for both $\mathrm{D}$ and DA, their respective anions $\mathrm{BF}_{4}{ }^{-}$and $\mathrm{Tf}_{2} \mathrm{~N}^{-}$were further investigated. Using these anions, $\mathrm{BF}_{4}^{-}$and $\mathrm{Tf}_{2} \mathrm{~N}^{-}, \mathrm{ILs}^{-}$ with distinct cations were evaluated to investigate the effect of their cations on the extraction yields of D and DA. As can be seen in Figure 3b, the greatest extraction ability of $40.12 \mathrm{mg} / \mathrm{g}$ for $\mathrm{D}$ and $15.27 \mathrm{mg} / \mathrm{g}$ for DA was obtained with $(\mathrm{BMIm}) \mathrm{BF}_{4}$. It was also found that $(\mathrm{Bpy}) \mathrm{BF}_{4}(\mathrm{D}=34.70 \mathrm{mg} / \mathrm{g}$ and $\mathrm{DA}=13.94 \mathrm{mg} / \mathrm{g})$, and $(\mathrm{BMIm}) \mathrm{Tf}_{2} \mathrm{~N}(\mathrm{D}=35.00 \mathrm{mg} / \mathrm{g}$ and $\mathrm{DA}=13.90 \mathrm{mg} / \mathrm{g})$ possess similar ability to extract both D and DA. However, other ILs showed very low ability to extract D and DA. Based on these results, it was concluded that the cations and anions of ILs simultaneously influence the extraction yields of D and DA.

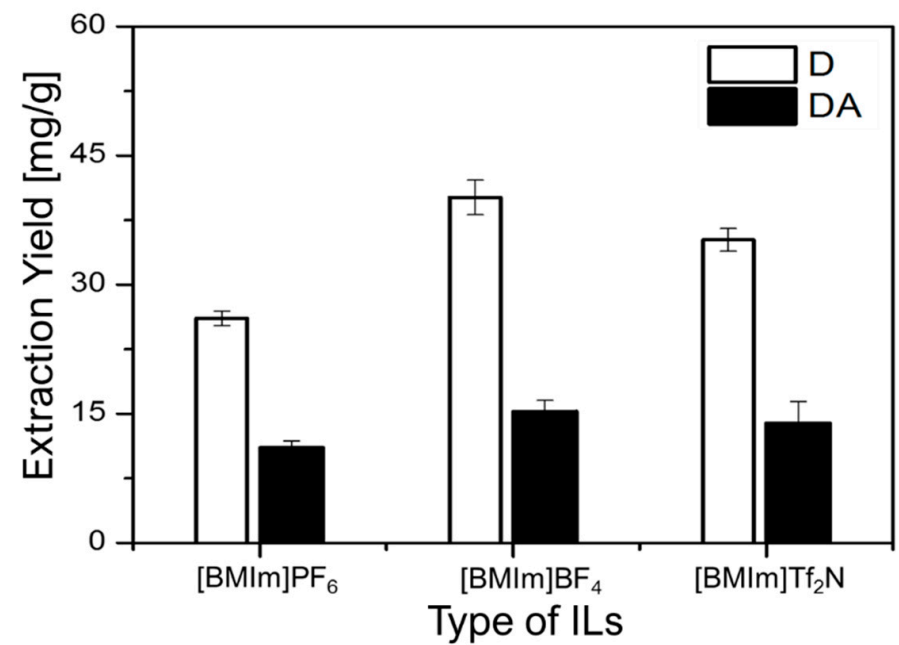

(a)

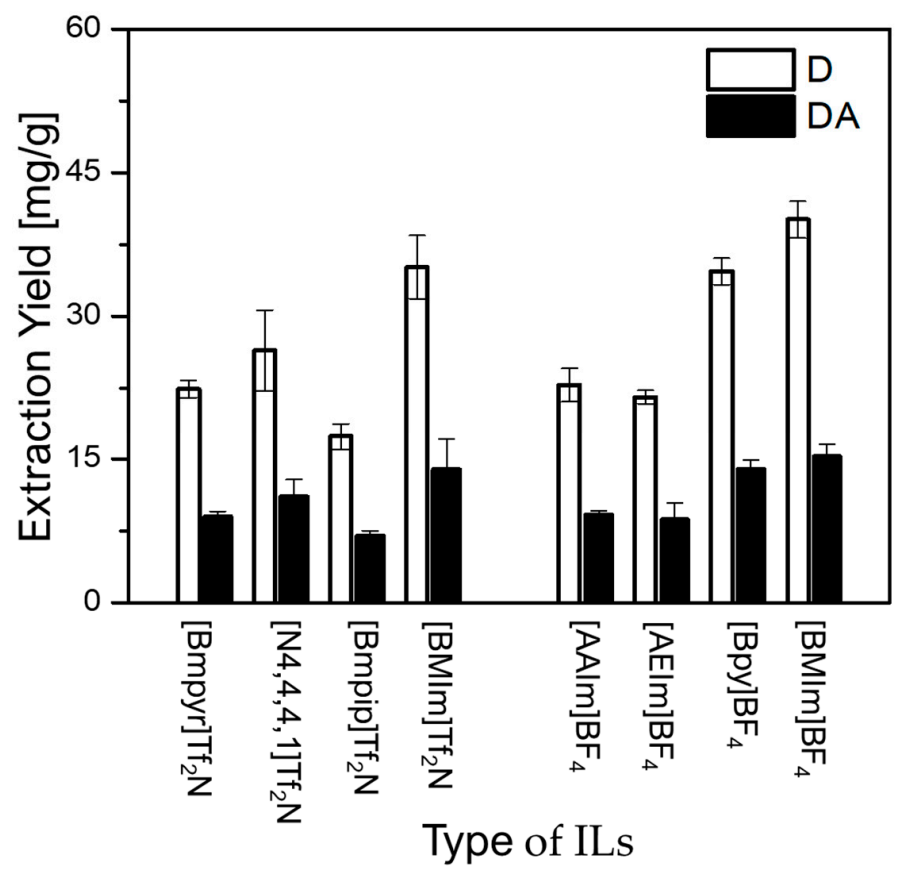

(b)

Figure 3. Effect of ILs on the extraction yields of D and DA: (a) effect of anions and (b) effect of cations. 


\subsection{Single Factor Experiments}

\subsubsection{Effect of Extraction Time}

The impact of time on the extraction yields of D and DA was investigated to optimize the extraction time, and thus, to avoid time consuming and incomplete extraction. Five samples of $1 \mathrm{~g}$ each were extracted with (BMIm) $\mathrm{BF}_{4}$ at $30{ }^{\circ} \mathrm{C}$, the solid-to-liquid ratio was fixed to $1 \mathrm{~g} / 6 \mathrm{~mL}$ and the rotational speed was $500 \mathrm{rpm}$. The time parameter was varied as follows: 30, 60, 90, 120, and $150 \mathrm{~min}$. As can be seen in Figure $4 \mathrm{a}, \mathrm{b}$, the yield of D increased from $38.26 \mathrm{mg} / \mathrm{g}(85.72 \%)$ at $30 \mathrm{~min}$ to $40.99 \mathrm{mg} / \mathrm{g}(90.02 \%)$ at $90 \mathrm{~min}$. In addition, the yield of DA increased from $15.68 \mathrm{mg} / \mathrm{g}(85.22 \%)$ at $30 \mathrm{~min}$ to $17.07 \mathrm{mg} / \mathrm{g}$ $(92.79 \%)$ at $90 \mathrm{~min}$. No significant increment in the yield of either D or DA could be observed with the increase of the extraction time. Thus, $90 \mathrm{~min}$ was selected as appropriate extraction time for further experiments.

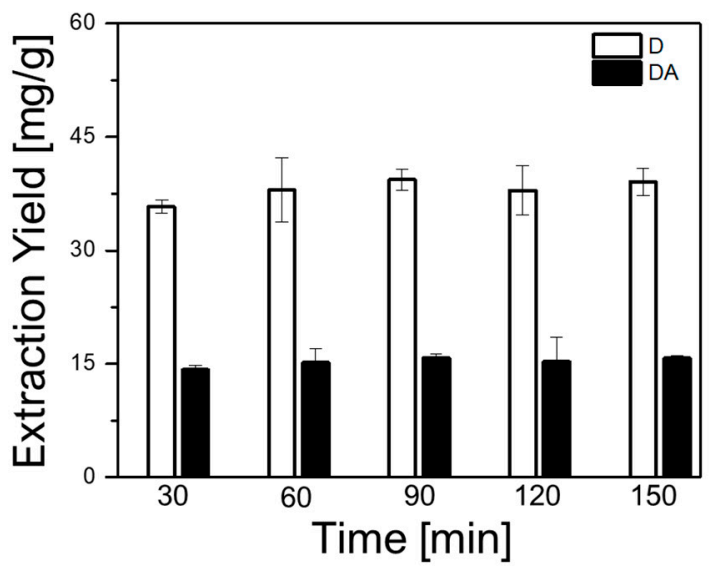

(a)

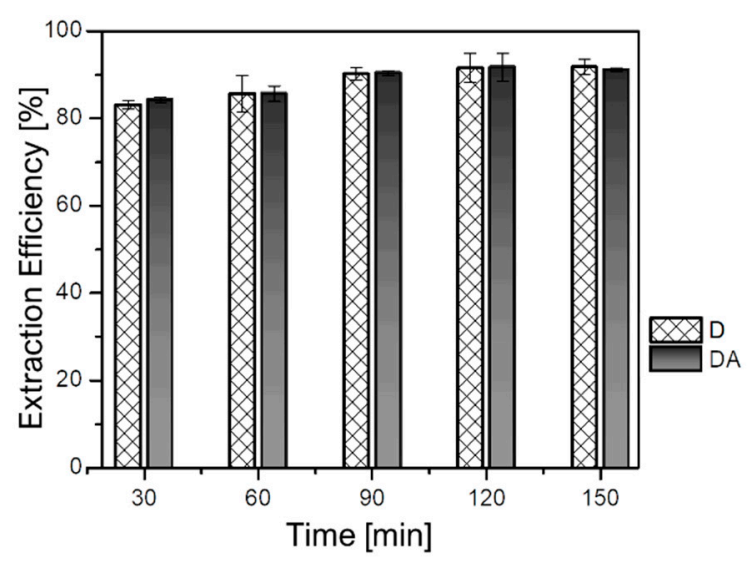

(b)

Figure 4. Effect of the extraction time on: (a) extraction yields of D and DA and (b) extraction efficiencies of D and DA.

\subsubsection{Effect of Solid-to-Liquid Ratio}

The effect of the solid-to-liquid ratio was evaluated to determine the optimum ratio for maximizing the extraction yield of D and DA, thus, avoiding both solvent waste and incomplete extraction of target components [25]. In this study, four samples of $1 \mathrm{~g}$ each were individually extracted at fixed temperature of $30^{\circ} \mathrm{C}$, and rotational speed of $500 \mathrm{rpm}$ for $90 \mathrm{~min}$. The solid-to-liquid ratio was set in the range from $1 \mathrm{~g} / 4 \mathrm{~mL}$ to $1 \mathrm{~g} / 10 \mathrm{~mL}$ to evaluate the effect of the solid-to-liquid ratio on the extraction yields of D and DA. As depicted in Figure 5a,b, the yields of D dramatically increased from $29.80 \mathrm{mg} / \mathrm{g}$ $(66.77 \%)$ at the ratios of $1 \mathrm{~g} / 4 \mathrm{~mL}$ to $40.49 \mathrm{mg} / \mathrm{g}(90.73 \%)$ at $1 \mathrm{~g} / 8 \mathrm{~mL}$. While that of DA dramatically increased from $11.90 \mathrm{mg} / \mathrm{g}(64.68 \%)$ to $16.93 \mathrm{mg} / \mathrm{g}$ (92.01\%) at the ratios of $1 \mathrm{~g} / 4 \mathrm{~mL}$ and $1 \mathrm{~g} / 8 \mathrm{~mL}$, respectively. However, a slight decrease in the yields of both D and DA, respectively, $40.40 \mathrm{mg} / \mathrm{g}$ $(90.53 \%)$ and $15.53 \mathrm{mg} / \mathrm{g}(84.42 \%)$, could be observed when the solid-to-liquid ratio was $1 \mathrm{~g} / 10 \mathrm{~mL}$. Hence, $1 \mathrm{~g} / 8 \mathrm{~mL}$ was selected as an appropriate solid-to-liquid ratio for further analysis. 


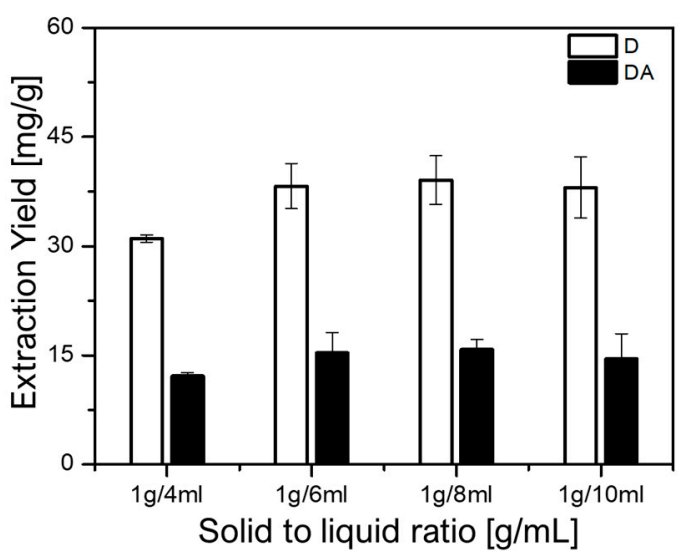

(a)

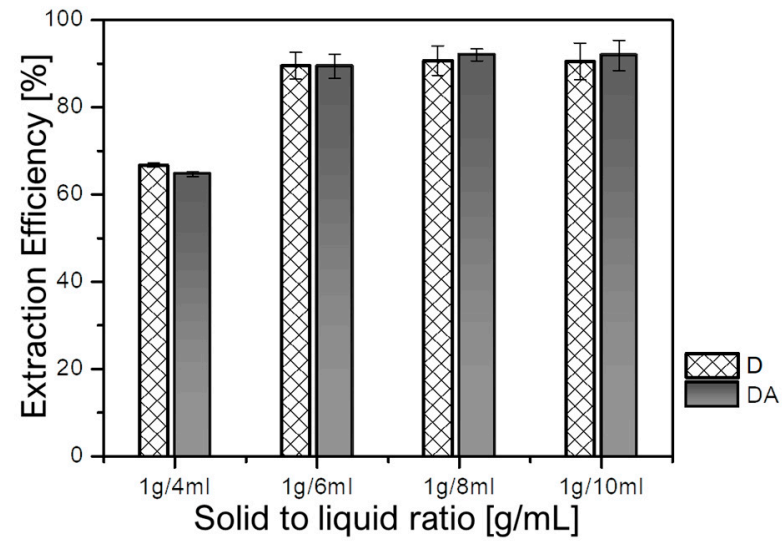

(b)

Figure 5. Effect of the solid-to-liquid ratio on: (a) extraction yields of D and DA and (b) extraction efficiencies of D and DA.

\subsubsection{Effect of Temperature}

It is well known that the rise in temperature can influence the extraction yield of target compounds by enhancing their solubility into the solvent. However, the increment of temperature can also cause degradation of heat-sensible compounds. Therefore, it is of great importance to investigate the impact of temperature on the extraction of target compounds. In this regard, the influence of temperature on the extraction yields of D and DA was evaluated at a constant rotational speed of $500 \mathrm{rpm}$ and a fixed solid-to-liquid ratio of $1 \mathrm{~g} / 8 \mathrm{~mL}$ for $90 \mathrm{~min}$. The temperature was varied as follows: 20, 30, 40, and $50{ }^{\circ} \mathrm{C}$. As depicted in Figure $6 \mathrm{a}, \mathrm{b}$, the yield of D augmented from $33.30 \mathrm{mg} / \mathrm{g}(74.62 \%)$ to 42.33 $\mathrm{mg} / \mathrm{g}(94.84 \%)$, while that of DA increased from $12.67 \mathrm{mg} / \mathrm{g}(68.85 \%)$ to $17.26 \mathrm{mg} / \mathrm{g}(93.80 \%)$ when the temperature was set from $20^{\circ} \mathrm{C}$ to $50{ }^{\circ} \mathrm{C}$, respectively.

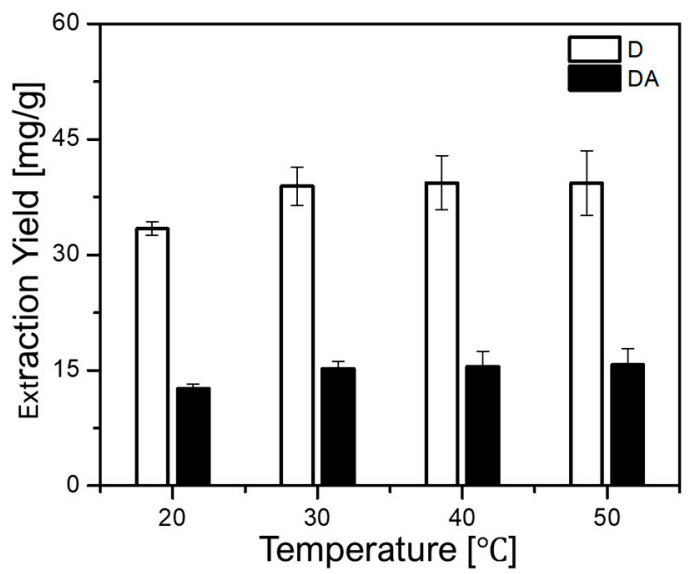

(a)

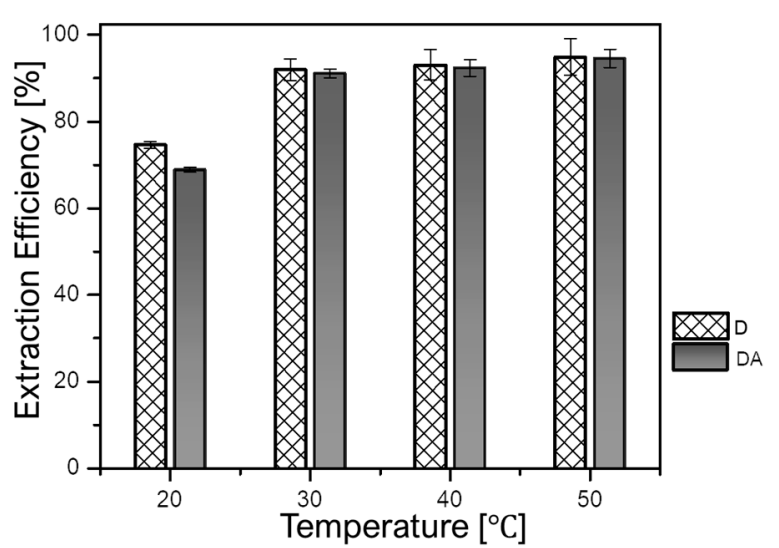

(b)

Figure 6. Effect of temperature on: (a) extraction yields of D and DA and (b) extraction efficiencies of D and DA.

\subsection{Optimization of Extraction Condition by Response Surface Method (RSM)}

Fifteen runs were conducted using RSM (Box-Behnken experimental design) to investigate the interaction between three variables: extraction time, temperature, and the solid-to-liquid ratio. The extraction time ranged from 30 to $120 \mathrm{~min}$, the temperature from 20 to $60^{\circ} \mathrm{C}$, and the solid-to-liquid 
ratio from $1 \mathrm{~g} / 4 \mathrm{~mL}$ to $1 \mathrm{~g} / 8 \mathrm{~mL}$. These conditions were set based on the results obtained from the previous section. The experimental conditions as well as the obtained responses are depicted in Table 1. In addition, below are the second-order polynomial equations for the determination of the extraction yields of $\mathrm{D}\left(\mathrm{Y}_{\mathrm{D}}\right)$ and $\mathrm{DA}\left(\mathrm{Y}_{\mathrm{DA}}\right) ; \mathrm{Y}_{\mathrm{D}}=-81.4555+0.309886 \mathrm{~A}+0.686104 \mathrm{~B}+79.2225 \mathrm{C}$ $+2.2428 \mathrm{~A}^{2}-0.011615 \mathrm{~B}^{2}-11.2171 \mathrm{C}^{2}+0.00096 \mathrm{AB}-0.056 \mathrm{AC}+0.08575 \mathrm{BC}$ (Actual $R^{2}=99.33 \%$ and Adjusted $\left.R^{2}=98.12 \%\right)$ and $Y_{\mathrm{DA}}=-94.5399+0.4458 \mathrm{~A}+0.812312 \mathrm{~B}+83.5383 \mathrm{C}-1.79012 \mathrm{~A}^{2}-$ $0.0109156 \mathrm{~B}^{2}-11.6538 \mathrm{C}^{2}-3.7500 \mathrm{AB}-0.07844 \mathrm{AC}+0.0822500 \mathrm{BC}$ (Actual $R^{2}=99.27 \%$ and Adjusted $R^{2}=97.96 \%$ ). Herein, A represents the extraction time, $\mathrm{B}$ the temperature, and $\mathrm{C}$ the solid-to-liquid ratio. The regression coefficient $\left(R^{2}\right)$ and the probability ( $p$-value) were used to confirm the quality and significance of the results.

Table 1. Extraction efficiencies of D and DA: design arrangements and responses.

\begin{tabular}{|c|c|c|c|c|c|c|c|}
\hline \multirow{2}{*}{ Run } & \multicolumn{3}{|c|}{ Parameters } & \multicolumn{4}{|c|}{ Responses } \\
\hline & $A(\min )$ & B $\left({ }^{\circ} \mathrm{C}\right)$ & $\mathrm{C}(\mathrm{g} / \mathrm{mL})$ & Predicted $Y_{1}$ & Observed $Y_{1}$ & Predicted $Y_{2}$ & Observed $Y_{2}$ \\
\hline 1 & $30(-1)$ & $40(0)$ & $4(-1)$ & 55.67 & 54.47 & 55.73 & 54.69 \\
\hline 2 & $75(0)$ & $60(1)$ & $8(1)$ & 88.41 & 88.77 & 90.45 & 91.37 \\
\hline 3 & $75(0)$ & $60(1)$ & $4(-1)$ & 62.68 & 62.94 & 65.12 & 65.87 \\
\hline 4 & $120(1)$ & $60(1)$ & $6(0)$ & 95.93 & 94.36 & 97.74 & 95.78 \\
\hline 5 & $75(0)$ & $40(0)$ & $6(0)$ & 88.78 & 87.92 & 90.65 & 90.84 \\
\hline 6 & $120(1)$ & $40(0)$ & $4(-1)$ & 77.24 & 78.54 & 80.14 & 81.35 \\
\hline 7 & $75(0)$ & $20(-)$ & $4(-1)$ & 61.21 & 60.85 & 62.10 & 61.18 \\
\hline 8 & $120(1)$ & $20(-)$ & $6(0)$ & 89.31 & 88.37 & 92.11 & 91.82 \\
\hline 9 & $75(0)$ & $40(0)$ & $6(0)$ & 88.78 & 89.37 & 90.65 & 89.91 \\
\hline 10 & $30(-1)$ & $40(0)$ & $8(1)$ & 83.01 & 81.71 & 84.84 & 83.63 \\
\hline 11 & $75(0)$ & $20(-)$ & $8(1)$ & 80.08 & 79.82 & 80.85 & 80.10 \\
\hline 12 & $75(0)$ & $40(0)$ & $6(0)$ & 88.78 & 89.04 & 90.65 & 91.20 \\
\hline 13 & $30(-1)$ & $60(1)$ & $6(0)$ & 77.68 & 78.62 & 81.06 & 81.35 \\
\hline 14 & $120(1)$ & $40(0)$ & $8(1)$ & 94.50 & 95.70 & 95.13 & 96.17 \\
\hline 15 & $30(-1)$ & $20(-)$ & $6(0)$ & 55.67 & 76.08 & 74.08 & 76.04 \\
\hline
\end{tabular}

Where A: Extraction time; B: Extraction temperature, C: Solid-to-liquid ratio, $\mathrm{Y}_{1}$ : Extraction efficiency of D; $\mathrm{Y}_{2}$ : Extraction efficiency of DA.

Table 2 List of the F-values and $p$-values calculated from the model. As can be seen in Table 2, the $F$-values for D and DA were 82.02 and 75.65, respectively, and the $p$-values were inferior to 0.0001 . The observed high $F$-values and the lower $p$-values indicate that the developed model was significant and that the chance for the model $F$-value of this size to occur as the statistical noise was less than $0.0001 \%$. The values of "lack of fit" of $p$-values and $F$-values ( 0.117 and 7.72 for D, and 0.117 and 11.85 for DA, respectively) indicate that the lack of fit was not significant. Generally, values of probability less than 0.05 or greater than 0.01 indicate that the model terms are significant or not significant. In this model, linear coefficients $A, B$, and $C$; quadratic term coefficients $B^{2}$ and $C^{2}$, and cross product coefficients $A C$ and $B C$ were significant with $p$-values inferior to 0.05 . However, quadratic term coefficient $A^{2}$ and cross product coefficient $\mathrm{AB}$ were not significant. Based on the overall obtained results, the model was confirmed very satisfactory. 
Table 2. Variance analysis for the quadratic response surface regression model.

\begin{tabular}{|c|c|c|c|c|c|}
\hline $\begin{array}{l}\text { D Extraction } \\
\text { Efficiency }\end{array}$ & $\begin{array}{l}\text { Degrees of } \\
\text { Freedom }\end{array}$ & $\begin{array}{l}\text { Sum of } \\
\text { Squares }\end{array}$ & Mean Square & F-Value & $p$-Value \\
\hline Model & 9 & 2146.41 & 238.49 & 82.02 & 0.001 \\
\hline A & 1 & 545.99 & 545.99 & 187.78 & 0.001 \\
\hline B & 1 & 47.87 & 47.87 & 16.46 & 0.001 \\
\hline $\mathrm{C}$ & 1 & 994.58 & 994.58 & 342.06 & 0.001 \\
\hline $\mathrm{A}^{2}$ & 1 & 5.07 & 0.008 & 0.00 & 0.961 \\
\hline $\mathrm{B}^{2}$ & 1 & 48.18 & 73.597 & 25.31 & 0.004 \\
\hline$C^{2}$ & 1 & 464.58 & 464.58 & 159.78 & 0.001 \\
\hline $\mathrm{AB}$ & 1 & 2.98 & 2.98 & 1.02 & 0.358 \\
\hline $\mathrm{AC}$ & 1 & 25.40 & 25.40 & 8.74 & 0.032 \\
\hline $\mathrm{BC}$ & 1 & 11.76 & 11.77 & 4.05 & 0.1 \\
\hline Residual & 5 & 14.54 & 2.91 & - & - \\
\hline Lack of fit & 3 & 13.38 & 4.461 & 7.72 & 0.117 \\
\hline Pure error & 2 & 1.16 & 0.58 & - & - \\
\hline Corrected Total & 14 & 2160.95 & - & - & - \\
\hline $\begin{array}{c}\text { DA Extraction } \\
\text { Efficiency }\end{array}$ & $\begin{array}{l}\text { Degrees of } \\
\text { Freedom }\end{array}$ & $\begin{array}{l}\text { Sum of } \\
\text { Squares }\end{array}$ & Mean Square & F-Value & $p$-Value \\
\hline Model & 9 & 2265.63 & 251.74 & 75.65 & 0.001 \\
\hline A & 1 & 602.22 & 602.22 & 180.98 & 0.001 \\
\hline B & 1 & 79.57 & 79.57 & 23.91 & 0.001 \\
\hline $\mathrm{C}$ & 1 & 971.96 & 971.96 & 292.10 & 0.001 \\
\hline$A^{2}$ & 1 & 0.00 & 0.05 & 0.00 & 0.961 \\
\hline $\mathrm{B}^{2}$ & 1 & 70.39 & 70.391 & 21.15 & 0.004 \\
\hline$C^{2}$ & 1 & 501.45 & 501.45 & 150.70 & 0.001 \\
\hline $\mathrm{AB}$ & 1 & 0.46 & 0.46 & 0.14 & 0.358 \\
\hline $\mathrm{AC}$ & 1 & 49.84 & 49.84 & 14.98 & 0.032 \\
\hline $\mathrm{BC}$ & 1 & 10.82 & 10.82 & 3.25 & 0.1 \\
\hline Residual & 5 & 16.64 & 3.33 & - & - \\
\hline Lack of fit & 3 & 15.75 & 5.25 & 11.85 & 0.117 \\
\hline Pure error & 2 & 0.89 & 0.44 & - & - \\
\hline Corrected Total & 14 & 2282.27 & - & - & - \\
\hline
\end{tabular}

The three-dimensional response surface plots for D and DA extraction efficiency are shown in Figure 7. In these figures, one can observe the influence of independent variables and their interactions on the extraction efficiencies of D and DA. The optimum extraction conditions proposed by the RSM were: extraction time $120 \mathrm{~min}$, temperature $59.98^{\circ} \mathrm{C}$, and solid-to-liquid ratio $1 \mathrm{~g} / 6.46 \mathrm{~mL}$; the predicted extraction yields were $43.74 \mathrm{mg} / \mathrm{g}(98 \%)$ for D and $18.03 \mathrm{mg} / \mathrm{g}(97.99 \%)$ for DA. However, the predicted conditions were slightly adjusted for the validation experiments as follows: extraction time $120 \mathrm{~min}$, temperature $60^{\circ} \mathrm{C}$, and solid-to-liquid ratio $1 \mathrm{~g} / 6.5 \mathrm{~mL}$. 


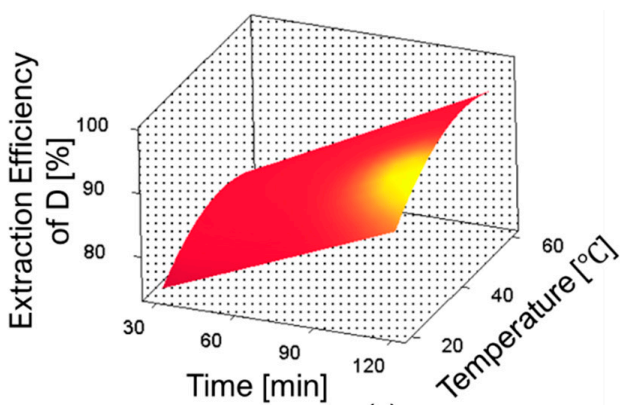

(a)

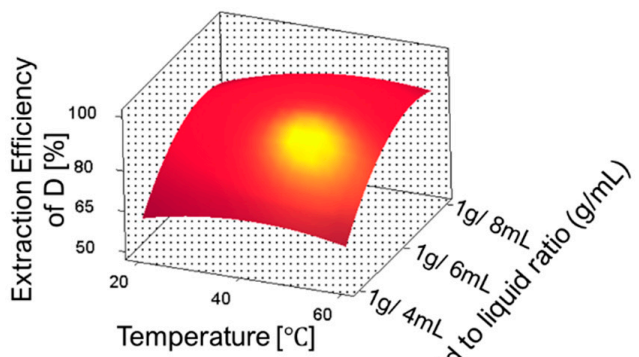

(b)

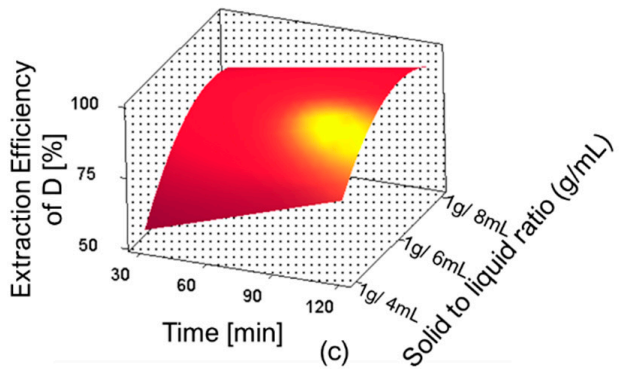

(c)

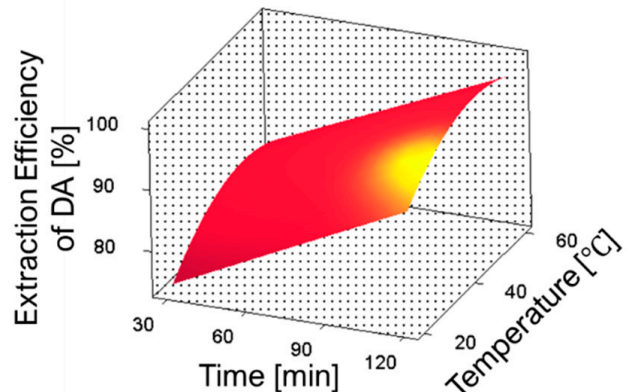

(d)

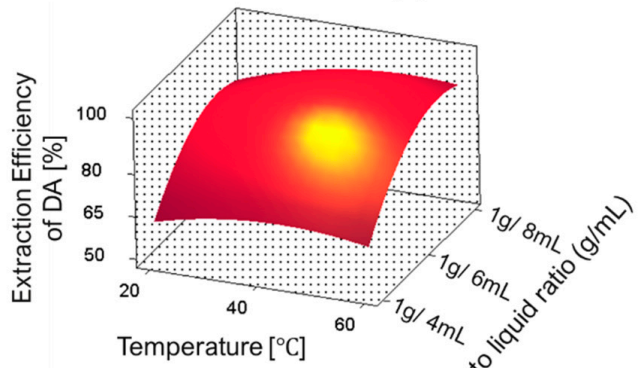

(e)

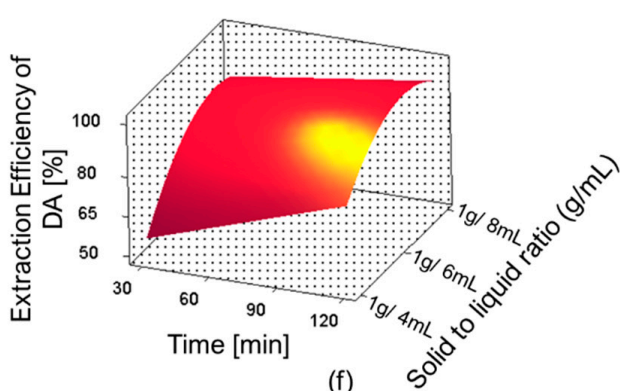

(f)

Figure 7. Response surface plots showing the interaction between single factors on the extraction efficiencies of D and DA. (a) effect of time and temperature on extraction efficiency of D, (b) effect of temperature and solid-to-liquid ratio on extraction efficiency of $\mathrm{D},(\mathbf{c})$ effect of time and solid-to-liquid ratio on extraction efficiency of $\mathrm{D},(\mathbf{d})$ effect of time and temperature on extraction efficiency of DA, (e) effect of temperature and solid-to-liquid ratio on extraction efficiency of DA and (f) effect of time and solid-to-liquid ratio on extraction efficiency of DA.

\subsection{Verification of the Optimal Extraction Method}

In order to evaluate the reproducibility and precision of the new developed extraction method, three samples of $1 \mathrm{~g}$ each were extracted under the adjusted optimal condition (extraction time $120 \mathrm{~min}$, temperature $60^{\circ} \mathrm{C}$, and solid-to-liquid ratio $1 \mathrm{~g} / 6.5 \mathrm{~mL}$ ) predicted by RSM. The results (Table 3) show that the yields of D and DA were $43.32 \mathrm{mg} / \mathrm{g}(97.09 \%)$ and $17.87 \mathrm{mg} / \mathrm{g}(97.07 \%)$, respectively. Based on these results, it can be assessed that the obtained experimental results are in great accordance with the results predicted by the RSM model (respectively, $43.74 \mathrm{mg} / \mathrm{g}$ for D and $18.03 \mathrm{mg} / \mathrm{g}$ for DA). Moreover, the experiments showed a good reproducibility and precision with RSD of $0.13 \%$ and $0.14 \%$ for the D and DA, respectively. 
Table 3. Verification of the optimized condition: reproducibility and precision.

\begin{tabular}{ccccc}
\hline Experiments & D Yield (mg/g) & DA Yield (mg/g) & $\begin{array}{c}\text { D Extraction } \\
\text { Efficiency (\%) }\end{array}$ & $\begin{array}{c}\text { DA Extraction } \\
\text { Efficiency (\%) }\end{array}$ \\
\hline 1 & 43.18 & 17.71 & 96.75 & 96.27 \\
2 & 43.36 & 17.89 & 97.16 & 97.23 \\
3 & 43.42 & 17.99 & 97.28 & 100.7 \\
Average & 43.32 & 17.86 & 97.09 & 97.07 \\
RSD (\%) & 0.2 & 0.14 & 0.28 & 2.35 \\
\hline
\end{tabular}

\subsection{Comparison of the (BMIm)BF ${ }_{4}$ Extraction Method with other Extraction Methods}

The (BMIm) $\mathrm{BF}_{4}$ extraction method was compared with other methods employed for the extraction of D and DA. Herein, A. gigas was extracted according to Lee's (2006) conventional reflux method (reflux extraction condition: $60 \% \mathrm{EtOH}$, temperature $95^{\circ} \mathrm{C}$, extraction time $6 \mathrm{~h}$ ) [9] and Kang's (2003) extraction method (extraction condition: $50 \% \mathrm{EtOH}$, temperature $60^{\circ} \mathrm{C}$, time $5 \mathrm{~h}$ ) [12]. Besides, A. gigas. was extracted with $100 \% \mathrm{EtOH}$ at the same extraction conditions with that of $(\mathrm{BMIm}) \mathrm{BF}_{4}$ (extraction time $120 \mathrm{~min}$, temperature $60^{\circ} \mathrm{C}$, and solid-to-liquid ratio $1 \mathrm{~g} / 6.5 \mathrm{~mL}$ ). The results illustrated in Table 4 reveal that the extraction yields of $\mathrm{D}$ and DA were greater with the (BMIm)BF 4 IL extraction method compared to other methods. The extraction time was also shorter than in other methods. Thus, it was assessed that the IL-based extraction method was most efficient in terms of the extraction yields of D and DA, and required less extraction time and solvent consumption when compared to other methods.

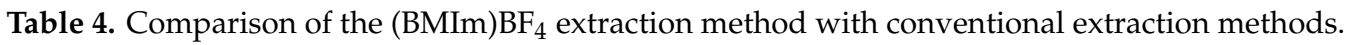

\begin{tabular}{ccccc}
\hline Extraction Method & Time (h) & Temperature $\left({ }^{\circ} \mathbf{C}\right)$ & D Yield $(\mathbf{m g} / \mathbf{g})$ & DA Yield (mg/g) \\
\hline (BMIm) $\mathrm{BF}_{4}$ & 2 & 60 & 43.32 & 17.86 \\
$60 \%$ EtOH Reflux & 6 & 95 & 29.80 & 13.55 \\
$50 \%$ EtOH & 5 & 60 & 35.46 & 15.22 \\
$100 \%$ EtOH & 2 & 60 & 18.24 & 8.75 \\
\hline
\end{tabular}

\subsection{Drowning out Crystallization of $D$ and $D A$ from $A$. gigas-(BMIm)BF $F_{4}$ Extraction Solution}

Drowning out crystallization experiments were performed in order to recover D and DA from the A. gigas-(BMIm) $\mathrm{BF}_{4}$ extraction solutions. Herein, the experiments were conducted using various anti-solvents ( $\mathrm{MeOH}, \mathrm{EtOH}, \mathrm{EA}, \mathrm{IPA}$, and DW) at a randomly selected $A$. gigas-IL extraction solution to anti-solvents ratio of $1: 5(v / v)$ at $20^{\circ} \mathrm{C}$ and $200 \mathrm{rpm}$ for $5 \mathrm{~h}$. As result, crystal could not be yielded when $\mathrm{MeOH}, \mathrm{EtOH}, \mathrm{EA}$, and IPA were used as anti-solvents. However, precipitates were obtained when DW was used as an anti-solvent. The obtained precipitates were analyzed by means of HPLC to determine whether D and DA were recovered well from the IL extraction solutions and to evaluate their purities. From the HPLC analysis results, the rates of recovery of D and DA as well as their total purity exceeded $80 \%$.

Furthermore, the correlation between the supersaturation level and the selective crystallization of $\mathrm{D}$ and DA was investigated to determine the reason influencing the occurrence and non-occurrence of $\mathrm{D}$ and DA crystallization when different anti-solvents were utilized. Supersaturation is the difference between the initial and the equilibrium concentration (solubility) of a certain compound. It is assumed as the driving force to induce crystallization. The supersaturation can be expressed as supersaturation level (S) and expressed as $S \sim C_{I} / C_{e q}$. Here, $C_{I}$ indicates the initial concentration and $C_{e q}$ the equilibrium concentration. Generally, spontaneous crystallization occurs at supersaturated state when $\mathrm{S}>1$; however, when $S<1$, it is an undersaturated state; therefore, a spontaneous crystallization cannot be induced. Additionally, crystallization is impossible when $S=1$ because the solution is in the saturated state, at this state, equilibrium is maintained. This shows that crystallization can occur only at a supersaturation level consistently higher than $1[38,39]$. Table 5 presents different values of $D$ and DA supersaturation levels $\left(\mathrm{S}_{\mathrm{D}}\right.$ and $\left.\mathrm{S}_{\mathrm{DA}}\right)$ when different anti-solvents $(\mathrm{MeOH}, \mathrm{EtOH}$, and $\mathrm{DW})$ 
were used. The result revealed the reason why crystallization was possible exclusively when DW was applied as anti-solvent. The fact that $S_{D}$ and $S_{D A}$ were lower when $\mathrm{MeOH}$ and $\mathrm{EtOH}$ were used as anti-solvents is presumed as the causes leading to the non-occurrence of precipitation. However, the high supersaturation levels, $S_{D}=5.28$ and $S_{D A}=46.6$, respectively, observed for D and DA when DW was the anti-solvent, impacted the crystallization of D and DA from the IL extraction solutions. This is because these supersaturation levels were satisfactory to induce spontaneous nucleation of target compounds, and consequently, their crystallization. Moreover, the simultaneous high supersaturation levels observed for both D and DA were assumed to influence their simultaneous nucleation, thus, the obtention of D and DA solid mixture.

Table 5. Supersaturation levels of D and DA in various A. gigas-IL extraction solution/anti-solvents $(1: 5(v / v))$.

\begin{tabular}{|c|c|c|c|c|c|c|}
\hline $\begin{array}{c}\left(\mathrm{BMIm} \mathrm{BF}_{4} / \text { Anti-Solvent }\right. \\
(v / v)\end{array}$ & $\begin{array}{c}\text { D. } \mathrm{C}_{\mathrm{I}} \\
(\mathrm{mg} / \mathrm{mL})\end{array}$ & $\begin{array}{l}\text { D. } \mathrm{C}_{\mathrm{eq}} \\
(\mathrm{mg} / \mathrm{mL})\end{array}$ & $S_{D}$ & $\begin{array}{c}\text { DA. } C_{I} \\
(\mathrm{mg} / \mathrm{mL})\end{array}$ & $\begin{array}{l}\text { DA. } \mathrm{C}_{\mathrm{eq}} \\
(\mathrm{mg} / \mathrm{mL})\end{array}$ & $S_{D A}$ \\
\hline (BMIm)BF4/MeOH & 1.11 & 0.90 & 1.23 & 0.42 & 0.36 & 1.17 \\
\hline$(\mathrm{BMIm}) \mathrm{BF}_{4} / \mathrm{EtOH}$ & 1.11 & 0.95 & 1.17 & 0.42 & 0.33 & 1.27 \\
\hline$(\mathrm{BMIm}) \mathrm{BF}_{4} / \mathrm{DW}$ & 1.11 & 0.21 & 5.28 & 0.42 . & 0.07 & 6.00 \\
\hline
\end{tabular}

In addition, drowning out crystallization experiments were carried out using various ratios of $A$. gigas-(BMIm)BF4 extraction solution to DW compositions $(1: 1,1: 3,1: 5,1: 10,1: 15,1: 20)$ to evaluate the effect of DW composition ratios on the crystallization behavior and recovery of both $\mathrm{D}$ and DA. The initial concentrations of D and DA in the A. gigas-(BMIm)BF4 extraction solution were $6.22 \mathrm{mg} / \mathrm{mL}$ and $2.631 \mathrm{mg} / \mathrm{mL}$, respectively. The temperature and the rotational speed were $20{ }^{\circ} \mathrm{C}$ and $200 \mathrm{rpm}$, respectively. From the results, it was found that when the ratio of $A$. gigas-(BMIm)BF $\mathrm{Br}_{4}$ extraction solution to DW was set to 1:1 (v/v), precipitates could not be induced even after three days of solution stirring. In addition, when the ratio of $A$. gigas-(BMIm) $\mathrm{BF}_{4}$ extraction solution to $\mathrm{DW}$ was set to $1: 3(v / v)$, precipitates were obtained after $20 \mathrm{~h}$ of solution stirring: however, in a much lower yield. Nevertheless, when the ratios of $A$. gigas-(BMIm) $\mathrm{BF}_{4}$ extraction solution to DW were set to 1:5, 1:10, 1:15, and 1:20 $(v / v)$, large quantities of solid materials could be induced very rapidly within only one to five hours of stirring. The obtained solid materials were analyzed via solution-state $1 \mathrm{H}-\mathrm{NMR}$ as presented in Figure 8. From the solution-state ${ }^{1} \mathrm{H}-\mathrm{NMR}$ data presented in Figure 8, it was ascertained that the solid materials obtained in this work were mixtures of sole D and DA precipitates.

The Table 6 presents the supersaturation level profile for D and DA monitored when the crystallization was induced at different ratios $(1: 1,1: 3,1: 5,1: 10,1: 15$, and 1:20) of A. gigas-(BMIm) BF 4 extraction solution to DW. These results deduced the reason leading to the non-occurrence of crystallization at the ratio $1: 1$ and to the occurrence of small product quantity at the ratio 1:3. As seen in Table 6, at the ratio of $1: 1$, the $S_{D}$ and $S_{D A}$ were 1.01 and 1.07, respectively. Although, these supersaturation levels $(S)$ were greater than $1(S>1)$, they are assumed inadequate to induce spontaneous nucleation of D and DA, and consequently, the reason for the non-occurrence of crystallization at this ratio. In addition, the supersaturation levels (S) for D and DA were $S_{D}=1.77$ and $S_{\mathrm{DA}}=1.83$, respectively, at 1:3 ratio. These supersaturation levels $(S)$ were considered capable to induce spontaneous nucleation of both D and DA. Thus, crystals formation was possible at this ratio. Moreover, as shown in Table 6, very high supersaturation levels (S), exceeding 4.5, were monitored for both D and DA at 1:5, 1:10, 1:15, and 1:20 ratios. Hence, the large supersaturation levels observed at these composition ratios were assumed to provoke the rapid and simultaneous precipitation of $\mathrm{D}$ and DA. 


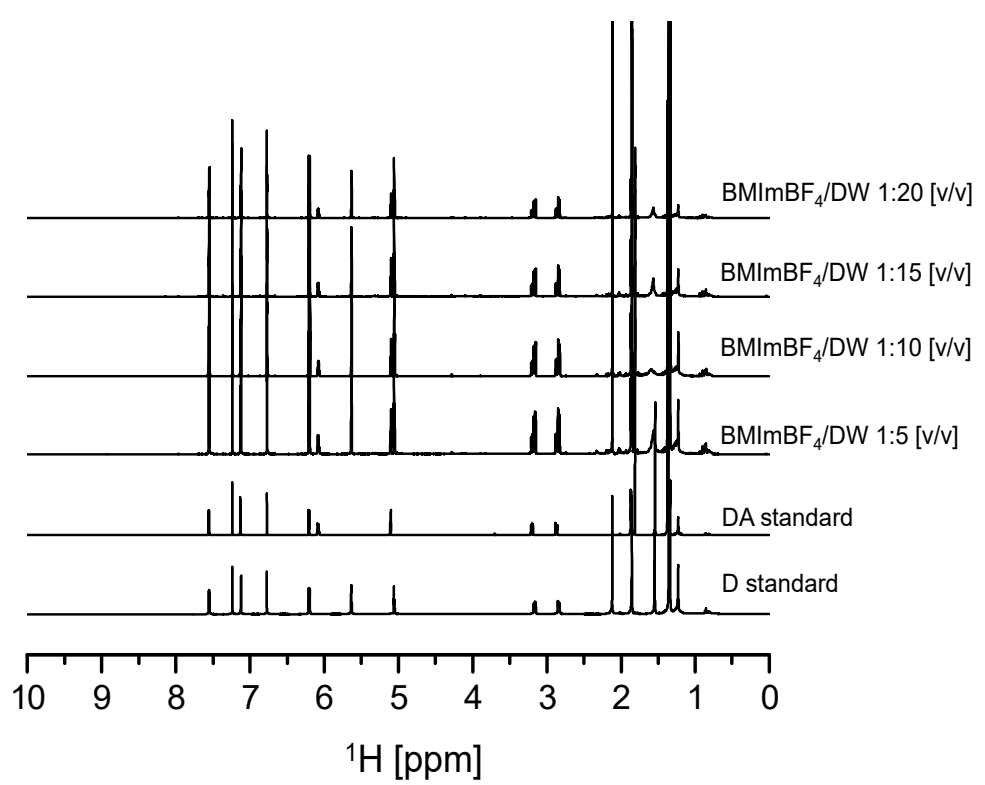

Figure 8. Solution-state ${ }^{1} \mathrm{H}-\mathrm{NMR}$ spectra for $\mathrm{D}$ and DA precipitated from A. gigas-(BMIm) $\mathrm{BF}_{4}$ extraction solution at different $\mathrm{DW}$ ratios $(v / v)(\mathrm{CDCl} 3)$.

Table 6. Supersaturation levels of D and DA in A. gigas-(BMIm)BF4 extraction solution/DW (v/v).

\begin{tabular}{|c|c|c|c|c|c|c|}
\hline$\left(\mathrm{BMIm} \mathrm{BF}_{4} / \mathrm{DW}(v / v)\right.$ & $\underset{(\mathrm{mg} / \mathrm{mL})}{\mathrm{D} \mathrm{C}_{\mathrm{I}}}$ & $\begin{array}{c}\mathrm{DC}_{\mathrm{eq}} \\
(\mathrm{mg} / \mathrm{mL})\end{array}$ & $S_{D}$ & $\underset{(\mathrm{mg} / \mathrm{mL})}{\mathrm{DA} \mathrm{C}_{\mathrm{I}}}$ & $\begin{array}{l}\mathrm{DA} \mathrm{C}_{\mathrm{eq}} \\
(\mathrm{mg} / \mathrm{mL})\end{array}$ & $\mathrm{S}_{\mathrm{DA}}$ \\
\hline $1: 1$ & 3.11 & 3.09 & 1.01 & 1.32 & 1.23 & 1.07 \\
\hline $1: 3$ & 1.56 & 0.88 & 1.77 & 0.66 & 0.36 & 1.83 \\
\hline $1: 5$ & 1.04 & 0.21 & 4.95 & 0.44 & 0.08 & 5.50 \\
\hline $1: 10$ & 0.57 & 0.06 & 9.5 & 0.24 & 0.01 & 24.00 \\
\hline 1:15 & 0.39 & 0.01 & 39.00 & 0.16 & 0.00 & 45.52 \\
\hline $1: 20$ & 0.29 & 0.01 & 29.00 & 0.13 & 0.00 & 56.88 \\
\hline
\end{tabular}

Table 7 illustrates the rates of recovery of D and DA at different ratios $(1: 3,1: 5,1: 10,1: 15$, and 1:20) of $A$. gigas-(BMIm) $\mathrm{BF}_{4}$ extraction solution to DW. The obtained result showed that crystallization was not induced when the ratio was 1:3; however, it was greatly achieved at ratios greater than 1:5. As can be seen in Table 7, the rates of recovery of D dramatically improved from $43.41 \%$ to $79.74 \%$, and those of DA dramatically improved from $45.25 \%$ to $81.75 \%$ at 1:3 and 1:5 ratios, respectively. The rates of recovery of $\mathrm{D}$ increased from $90.35 \%$ to $97.42 \%$ when the ratios were set to $1: 10$ and 1:15, respectively. Also, the rates of recovery of DA increased from $95.82 \%$ to $97.71 \%$ at ratios of $1: 10$ and $1: 15$, respectively. At last, the rates of recovery of $\mathrm{D}$ and $\mathrm{DA}$ at $1: 20$ were recorded as $\mathrm{D}=96.62 \%$ and $\mathrm{DA}=98.09 \%$, respectively. The increase of D and DA recovery rates was attributed to the change in their supersaturation levels when the ratio of DW was increased (Table 6).

Table 7. Concentration difference $(\Delta C)$ and yields of $\mathrm{D}$ and DA depending on the DW composition ratio.

\begin{tabular}{ccccc}
\hline $\begin{array}{c}(\mathrm{BMIm}) \mathbf{B F}_{4} / \mathrm{DW} \\
(\boldsymbol{v} / \boldsymbol{v})\end{array}$ & $\boldsymbol{\Delta} \mathbf{C}_{\mathbf{D}}(\mathbf{m g})$ & $\mathbf{D}$ Yield (\%) & $\Delta \mathbf{C}_{\mathbf{D A}}(\mathbf{m g})$ & DA Yield (\%) \\
\hline $1: 3$ & 2.70 & 43.41 & 1.19 & 45.25 \\
$1: 5$ & 4.96 & 79.74 & 2.15 & 81.75 \\
$1: 10$ & 5.62 & 90.35 & 2.52 & 95.82 \\
$1: 15$ & 6.06 & 97.42 & 2.57 & 97.71 \\
$1: 20$ & 6.01 & 96.62 & 2.58 & 98.09 \\
\hline
\end{tabular}


Moreover, the total purity of D and DA in products obtained at 1:5, 1:10, 1:15, and 1:20 ratios of A. gigas-(BMIm) $\mathrm{BF}_{4}$ extraction solution to DW was determined. These ratios were selected as they demonstrated high recovery of D and DA. The results are illustrated in Table 8. As can be observed in Table 8 , the average total purity of D and DA was of approximatively $97 \%$ in the products.

Table 8. Total Purity of D and DA in the products.

\begin{tabular}{cccc}
\hline $\mathbf{( B M I m ) B F} / \mathbf{D W}(\boldsymbol{v} / \boldsymbol{v})$ & $\begin{array}{c}\text { Total Weight of Product } \\
(\mathbf{m g})\end{array}$ & $\begin{array}{c}\text { Total Content of D and } \\
\mathbf{D A}(\mathbf{m g})\end{array}$ & $\begin{array}{c}\text { Total Purity of D and } \\
\mathbf{D A}(\%)\end{array}$ \\
\hline $1: 5$ & 7.35 & 7.11 & 96.73 \\
$1: 10$ & 8.39 & 8.14 & 97.02 \\
$1: 15$ & 8.85 & 8.63 & 97.51 \\
$1: 20$ & 8.83 & 8.59 & 97.28 \\
\hline
\end{tabular}

From this study, an efficient and adequate method for the rapid and selective separation of D and DA from $A$. gigas using (BMIm) $\mathrm{BF}_{4}$ as extraction solvent and $\mathrm{DW}$ as anti-solvent was developed. Only these ratios of $A$. gigas-(BMIm)BF $\mathrm{BF}_{4}$ extraction solution to DW, 1:5 1:10, 1:15, and 1:20, were found favorable to produce D and DA with high yields and high purities. The separation scheme of D and DA from $A$. gigas using IL ((BMIm) $\left.\mathrm{BF}_{4}\right)$ as extraction solvent and drowning out crystallization for the recovery of D and DA is illustrated in the Scheme 1.

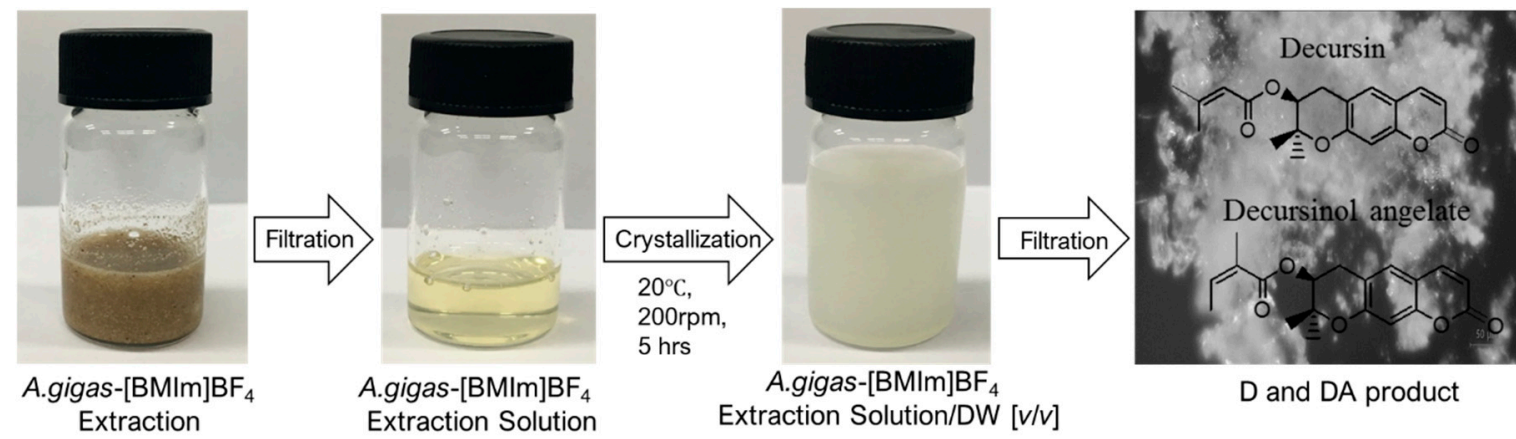

Scheme 1. Scheme for separating D and DA from A. gigas using (BMIm)BF 4 and crystallization.

\section{Materials and Methods}

\subsection{Reagents and Materials}

Decursin (D) and decursinol angelate (DA) standards were purchased from Chengdu Biopurify Phytochemicals Ltd. (China), and their purities were $98.12 \%$ and $98.27 \%$, respectively. The roots of Angelica gigas Nakai (A. gigas) were purchased from a local market in Seoul (2017) and identified by Professor Jinwoong Kim of Seoul National University. A voucher (GEL-AG02) was deposited in the Herbarium of the College of Pharmacy, Seoul National University (Seoul, South Korea). Ionic liquids including 1-butyl-1-methylpyrrolidinium bis(trifluoromethanesulfonyl) imide (Bmpyr)Tf ${ }_{2} \mathrm{~N}, 1-$ butyl-1methylpiperidinium bis(trifluoromethanesulfonyl) imide (Bmpip) $\mathrm{Tf}_{2} \mathrm{~N}$, tributylmethylammonium bis (trifluoromethanesulfonyl) imide $(\mathrm{N} 4,4,4,1) \mathrm{Tf}_{2} \mathrm{~N}$, 1-allyl-3-ethylimidazolium tetrafluoroborate (AEIm) $\mathrm{BF}_{4}, 1$,3-diallylimidazolium tetrafluoroborate $(\mathrm{AAIm}) \mathrm{BF}_{4}$, and 1-butylpyridinium tetrafluoro borate $\left(\mathrm{Bpy}_{\mathrm{B}} \mathrm{BF}_{4}\right.$ were purchased from Kanto Chem Co., Inc. (Tokyo, Japan). 1-butyl-3-methylimidaz olium bis(trifluoromethylsulfonyl) imide (BMIm) $\mathrm{Tf}_{2} \mathrm{~N}$, 1-butyl-3-methylimidazolium hexafluorop hosphate (BMIm) $\mathrm{PF}_{6}$ and 1-butyl-3-methylimidazolium tetrafluoroburate (BMIm) $\mathrm{BF}_{4}$ were purchased from A-star Co., Ltd. (Ulsan, Korea). The HPLC grade deionized water (DW), acetonitrile (ACN), phosphoric acid (purity > 99\%), analytical grade methanol $(\mathrm{MeOH})$, ethanol $(\mathrm{EtOH})(\mathrm{purity}>98 \%)$, ethyl acetate (EA), and isopropyl alcohol (IPA) were all purchased from DaeJung Chem. Co., Ltd. (Siheung, South Korea). 


\subsection{Methods}

\subsubsection{Extraction Procedure and Determination of Extraction Yields}

The dried roots of $A$. gigas were uniformly grounded and sieved through a 50 mesh sieve (particle size $<300 \mu \mathrm{m})$. Nine samples of $1 \mathrm{~g}$ each were extracted with a known volume of different ILs such as $\left(\right.$ Bmpyr) $\mathrm{Tf}_{2} \mathrm{~N},(\mathrm{Bmpip}) \mathrm{Tf}_{2} \mathrm{~N},(\mathrm{~N} 4,4,4,1) \mathrm{Tf}_{2} \mathrm{~N},(\mathrm{BMIm}) \mathrm{Tf}_{2} \mathrm{~N},\left(\mathrm{BMIm}^{2} \mathrm{PF}_{6},(\mathrm{BMIm}) \mathrm{BF}_{4},(\mathrm{AEIm}) \mathrm{BF}_{4}\right.$, (AAIm) $\mathrm{BF}_{4}$, and (Bpy)BF $\mathrm{BF}_{4}$ at room temperature $\left(20^{\circ} \mathrm{C}\right)$ and constant rotational speed $(500 \mathrm{rpm})$ for $2 \mathrm{~h}$. The purpose was to evaluate the ability of distinct ILs (the effects of their anions and cations) on the extraction yields of D and DA, and to select the relevant IL. After extraction, all samples were subjected to vacuum filtration to collect the $A$. gigas-IL extraction solutions which were then analyzed via HPLC to determine the contents of D and DA in the extracts. After selecting the relevant IL, the abovementioned parameters were cautiously examined to determine the optimal extraction condition for maximizing the extraction yields of D and DA. Each experiment was conducted in triplicate. The extraction yield was calculated using the following equation:

$$
\text { Extraction yield }\left(\frac{\mathrm{mg}}{\mathrm{g}}\right)=\frac{\text { Aount of D or DA in the extract }(\mathrm{mg})}{\text { Total amount of D or DA in dry weight mass of A.gigas }(\mathrm{g})}
$$

\subsubsection{Optimization of the Extraction Method using Response Surface Methodology (RSM)}

In order to maximize the extraction yields of D and DA, interaction between variables was investigated and optimized by response surface methodology employing Box-Behnken design of Minitab 16 software (Minitab LLC, PA, USA). The experimental factors were set based on the experimental results obtained from the single factors experiments, as follows: extraction time (30, 75 , and $120 \mathrm{~min})$, temperature $\left(20,40\right.$, and $\left.60^{\circ} \mathrm{C}\right)$ and solid-to-solvent ratio $(1 \mathrm{~g} / 4 \mathrm{~mL}, 1 \mathrm{~g} / 6 \mathrm{~mL}$, and $1 \mathrm{~g} / 8 \mathrm{~mL}$ ). The significance level was set at $p<0.05$. The extraction yield was calculated using Equation (1).

\subsubsection{Sample Solutions Preparation}

After extraction, all samples were subjected to vacuum filtration to collect the A. gigas-(BMIm) $\mathrm{BF}_{4}$ extraction solution. Afterwards, $10 \mu \mathrm{L}$ of each filtrate was diluted with $100 \%$ of $\mathrm{MeOH}$ to obtain sample solutions of known concentration. The prepared solutions were filtered through $0.45 \mu \mathrm{m}$ membrane filter and then injected into the HPLC system. The HPLC analysis experiments were performed in triplicate.

\subsubsection{High-Performance Liquid Chromatographic (HPLC) Measurements for the Quantitative} Determination of D and DA

An Agilent HPLC equipment (Agilent 1260, Santa Clara, CA, USA) was used to determine the total extraction amounts and concentrations of D and DA. A Hydrosphere C-18 column $(250 \times 4.6 \mathrm{~mm}$, $5 \mu \mathrm{m}, 12 \mathrm{~nm}, \mathrm{YMC}$, Kyoto, Japan) was used in this analysis. The mobile phase composition was DW (A) and ACN (B) under the gradient elution condition of: 0.00-5.00 $\mathrm{min}, 15-30 \% \mathrm{~B} ; 5.10-30.00 \mathrm{~min}$, $50-75 \% \mathrm{~B} ; 30.10-40.00 \mathrm{~min}, 75 \% \mathrm{~B} ; 40.10-50.00 \mathrm{~min}, 15 \% \mathrm{~B}$. The flow rate and the injection volume were $0.8 \mathrm{~mL} / \mathrm{min}$ and $10 \mu \mathrm{L}$, respectively. The detection absorbance was $330 \mathrm{~nm}$, while the column temperature and the sample running time were $30^{\circ} \mathrm{C}$ and $50 \mathrm{~min}$, respectively. The chromatographic peaks of D and DA contained in the A. gigas-IL extraction solutions were confirmed by comparing their retention times and UV spectra with those of the reference standards and was determined by the regression equations of the calibration curves. The calibration curves constructed on three consecutive runs exhibited a good linearity $\left(R^{2}=0.996, n=7\right.$ for $\mathrm{D}$ and $R^{2}=0.999, n=7$ for DA) in the range of 2.5 to $100 \mu \mathrm{g} / \mathrm{mL}$. The limit of detection (LOD) and the limit of quantification (LOQ) were, respectively, $0.316 \mu \mathrm{g}$ and $0.958 \mu \mathrm{g}$ for D and $0.764 \mu \mathrm{g}$ and $2.316 \mu \mathrm{g}$ for DA (Table 9). 
Table 9. Linear ranges, correlation coefficients, LOD, and LOQ of calibration curves.

\begin{tabular}{cccccc}
\hline Analytes & Linearities & $\begin{array}{c}\text { Correlation } \\
\text { Coefficient }\end{array}$ & $\begin{array}{c}\text { Calibration } \\
\text { Range }(\mu \mathrm{g} / \mathrm{mL})\end{array}$ & $\begin{array}{c}\text { LOD } \\
(\mu \mathrm{g} / \mathrm{mL})\end{array}$ & $\begin{array}{c}\text { LOQ } \\
(\mu \mathrm{g} / \mathrm{mL})\end{array}$ \\
\hline $\mathrm{D}$ & $\mathrm{Y}=28.994 \mathrm{x}-16.247$ & 0.996 & $2.5 \sim 100$ & 0.316 & 0.958 \\
$\mathrm{DA}$ & $\mathrm{Y}=30.314 \mathrm{x}+29.732$ & 0.999 & $2.5 \sim 100$ & 0.764 & 2.316 \\
\hline
\end{tabular}

\subsubsection{Quantitative Determination of D and DA in the Roots of A. gigas}

In order to determine the total amounts of D and DA in the roots of $A$. gigas roots, two samples of $A$. gigas roots of $1 \mathrm{~g}$ each were extracted using $100 \mathrm{~mL}$ of $95 \%$ ethanol (EtOH) for $12 \mathrm{~h}$ at room temperature. The experiment was triplicated, and then, the collected solutions of EtOH were separately mixed and concentrated in vacuo for subsequent HPLC analysis. From this study, the obtained contents of $\mathrm{D}$ and DA in $1 \mathrm{~g}$ of $A$. gigas were, respectively, $44.63 \mathrm{mg} / \mathrm{g}(4.46 \%$ of $A$. gigas raw material) and $18.4 \mathrm{mg} / \mathrm{g}$ (1.84\% of $A$. gigas raw material). Thus, these respective contents of D and DA $(44.63 \mathrm{mg} / \mathrm{g}$ and $18.40 \mathrm{mg} / \mathrm{g}$ ) were considered as reference (100\% content) for further comparative experiments.

\subsubsection{Selective Crystallization of D and DA from A. gigas-IL Extraction Solution}

Drowning out crystallization experiments were conducted to recover D and DA from the $A$. gigas-IL extraction solution. However, crystal formation as well as a rapid and effective recovery of D and DA could be observed exclusively from $(\mathrm{BMIm}) \mathrm{BF}_{4}$ when $\mathrm{DW}$ was used as an anti-solvent. The obtained crystals were subjected to solution-state ${ }^{1} \mathrm{H}-\mathrm{NMR}$ measurements to confirm the nature of the obtained crystals. Afterwards, crystallization experiments were carried out at fixed A. gigas-IL extraction solution and varied DW anti-solvent fractions for $5 \mathrm{~h}$ at room temperature $\left(20^{\circ} \mathrm{C}\right)$ and $200 \mathrm{rpm}$ for investigating the effect of DW ratios on the selective crystallization and recovery rate of $\mathrm{D}$ and DA. The ratio of the solvent to anti-solvent, $A$. gigas-IL extraction solution to DW, was set to $1: 1,1: 3,1: 5,1: 10,1: 15$, and 1:20 $(v / v)$. All obtained crystals were thoroughly washed to remove the remaining $\mathrm{IL}$, dried in vacuo at $40{ }^{\circ} \mathrm{C}$ for $24 \mathrm{~h}$, and then stored at $4{ }^{\circ} \mathrm{C}$ prior to the analysis. The rate of recovery and purity of $\mathrm{D}$ and $\mathrm{DA}$ were determined by the following equations:

$$
\begin{gathered}
\text { Recovery }(\%)=\frac{\text { Amount of D or DA in the product }(\mathrm{mg})}{\text { Initial amount of D or DA in the IL extract }(\mathrm{mg})} \times 100 \\
\text { Purity }(\%)=\frac{\text { Total amount of D and DA in the product }(\mathrm{mg})}{\text { Total amount of the product }(\mathrm{mg})} \times 100
\end{gathered}
$$

\subsubsection{Solution-State Nuclear Magnetic Resonance Spectroscopy (Solution-State NMR)}

The Solution-state ${ }^{1} \mathrm{H}-\mathrm{NMR}$ measurements were conducted on $500 \mathrm{MHz}$ and $800 \mathrm{MHz}$ NMR Spectrometer (Advance, Bruker, Billerica, MA, USA) to confirm the chemical structures of D and DA solids precipitated from $(\mathrm{BMIm}) \mathrm{BF}_{4}$. All Samples were dissolved in $\mathrm{CDCl}_{3}$ prior to analysis.

\section{Conclusions}

The present work developed a rapid and efficient method for the separation of D and DA from the roots of $A$. gigas using ILs as extraction solvent. The extraction conditions were optimized by RSM. Compared to other ILs and commonly applied organic solvents such as EtOH, (BMIm)BF showed a greater extraction ability of $43.32 \mathrm{mg} / \mathrm{g}(97.06 \%)$ for D and $17.87 \mathrm{mg} / \mathrm{g}(97.12 \%)$ for DA. In addition, a mixture of sole D and DA (total purity of $97 \%$ ) could be obtained very rapidly from $A$. gigas-(BMIm) $\mathrm{BF}_{4}$ extraction solution when DW was used as an anti-solvent. The rates of recovery of $\mathrm{D}$ and DA were greater than $95 \%$ when the ratios of $A$. gigas-(BMIm)BF $\mathrm{BF}_{4}$ extraction solution to DW were greater than 1:5. In conclusion, the developed approach revealed a remarkable effectiveness compared to conventional methods as, great extraction yields, high purity, and satisfactory recovery of D and DA 
could be achieved simply and rapidly. Through the findings it was confirmed the capability of ILs for the separation of natural products. To our knowledge, this is the first time that an efficient method using ILs in combination with crystallization was achieved for the obtention of high-purity D and DA from A. gigas. The developed technique is assumed crucial in the pharmaceutical industry for the effective obtention of high-yield and high-purity D and DA from A. gigas.

Author Contributions: Conceptualization, A.N.K., J.-H.A., and K.J.; methodology, A.N.K, J.-H.A., K.Y.L., and K.J.; software, A.N.K. and J.-H.A.; validation, A.N.K, J.-H.A., and C.L.; formal analysis, A.N.K, J.-H.A., K.Y.L., and C.L.; investigation, A.N.K., J.-H.A., and K.Y.L.; data curation, A.N.K., J.-H.A., C.L., Y.-G.S., K.Y.L., Y.-W.C. and K.J.; writing-original draft preparation, A.N.K. and J.-H.A.; writing-review and editing, A.N.K., J.-H.A., C.L., Y.-G.S., K.Y.L., Y.-W.C., and K.J.; supervision, Y.-G.S., Y.-W.C., and K.J.

Funding: This work was supported by the National Research Foundation of Korea (NRF) funded by the Korean government (MSIT) through grants NRF-2016R1C1B2016008 and NRF-2018R1A5A2023127.

Conflicts of Interest: The authors declare no conflict of interest.

\section{References}

1. Woo, W.S.; Lee, C.K.; Shin, K.H. Isolation of Drug Metabolism Modifiers from Roots of Angelica koreana. Planta Med. 1982, 45, 234-236. [CrossRef] [PubMed]

2. Deng, S.; Chen, S.N.; Yao, P.; Nikolic, D.; van Breemen, R.B.; Bolton, J.L.; Fong, H.H.S.; Farnsworth, N.R.; Pauli, G.F. Serotonergic Activity-Guided Phytochemical Investigation of the Roots of Angelica sinensis. J. Nat. Prod. 2006, 69, 536-541. [CrossRef] [PubMed]

3. Jeong, S.Y.; Kim, H.M.; Lee, K.H.; Kim, K.Y.; Huang, D.S.; Kim, J.H.; Seong, R.S. Quantitative Analysis of Marker Compounds in Angelica gigas, Angelica sinensis, and Angelica acutiloba by HPLC/DAD. Chem. Pharm. Bull. (Tokyo) 2015, 63, 504-511. [CrossRef] [PubMed]

4. Son, S.H.; Park, K.K.; Park, S.K.; Kim, Y.C.; Kim, Y.S.; Lee, S.K.; Chung, W.Y. Decursin and decursinol from Angelica gigas inhibit the lung metastasis of murine colon carcinoma. Phytother. Res. 2011, 25, 959-964. [CrossRef] [PubMed]

5. Jiang, C.; Guo, J.; Wang, Z.; Xiao, B.; Lee, H.J.; Lee, E.O.; Kim, S.H.; Lu, J. Decursin and decursinol angelate inhibit estrogen-stimulated and estrogen-independent growth and survival of breast cancer cells. Breast Cancer Res. 2007, 9, R77. [CrossRef] [PubMed]

6. Li, L.; Li, W.; Jung, S.W.; Lee, Y.W.; Kim, Y.H. Protective effects of decursin and decursinol angelate against amyloid $\beta$-protein-induced oxidative stress in the PC12 cell line: The role of Nrf2 and antioxidant enzymes. Biosci. Bbiotechnol. Biochem. 2011, 75, 434-442. [CrossRef]

7. Heo, J.S.; Cha, J.Y.; Kim, H.W.; Ahn, H.Y.; Eom, K.E.; Heo, S.J.; Cho, Y.S. Bioactive Materials and Biological Activity in the Extracts of Leaf, Stem mixture and Root from Angelica gigas Nakai. J. Life Sci. 2010, 20, 750-759.

8. Cho, J.H.; Kwon, J.E.; Cho, Y.; Kim, I.; Kang, S.C. Anti-inflammatory effect of Angelica gigas via heme oxygenase (HO)-1 expression. Nutrients 2015, 74, 862-4874. [CrossRef]

9. Reddy, C.S.; Kim, S.C.; Hur, M.; Kim, Y.B.; Park, C.G.; Lee, W.M.; Jang, J.K.; Koo, S.C. Natural Korean Medicine Dang-Gui: Biosynthesis, Effective Extraction and Formulations of Major Active Pyranocoumarins, Their Molecular Action Mechanism in Cancer, and Other Biological Activities. Molecules 2017, 22, 2170. [CrossRef]

10. Lee, G.D.; Lee, S.Y.; Kim, K.S.; Kwon, J.H. The optimization of microwave-assisted extraction of decursin from Angelica gigas Nakai root. Int. J. Food Sci. Tech. 2006, 41, 737-742. [CrossRef]

11. Cho, S.K.; Abd El-Aty, A.M.; Choi, J.H.; Kim, M.R.; Shim, J.H. Optimized conditions for the extraction of secondary volatile metabolites in Angelica roots by accelerated solvent extraction. J. Pharm. Biomed. Anal. 2007, 44, 1154-1158. [CrossRef] [PubMed]

12. Kim, K.M.; Jung, J.Y.; Hwang, S.W.; Kim, M.J.; Kang, J.S. Isolation and purification of decursin and decursinol angelate in Angelica gigas Nakai. J. Korean Soc. Food Sci. Nutr. 2009, 38, 653-656. [CrossRef]

13. Kang, Y.G.; Lee, J.H.; Chae, H.J.; Kim, D.H.; Lee, S.H.; Park, S.Y. HPLC Analysis and Extraction Methods of Decursin and Decursinol Angelate in Angelica gigas Roots. Korean J. Pharmacogn. 2003, 34, 201-205.

14. Lee, S.H. Studies on the Establishment of Extraction conditions and Isolation of Decursin from Angelica gigas Nakai. Ph.D. Thesis, Hankyong National University, Gangwon Province, South Korea, February 2006. 
15. Lee, H.J.; Jeong, H.S.; Park, C.G.; Lee, J.H.; Park, C.B.; Kim, C.T.; Choi, A.J. Physiochemical Characteristics of Extruded Angelica gigas Nakai Depending on the Extrusion Processing Parameter. Korean J. Med. Crop Sci. 2014, 22, 349-362. [CrossRef]

16. Johnson, K.E.; Xiao, L.; Driver, G. Significance of Cations in Ionic Liquids Chemistry. In Ionic liquids: Industrial Applications to Green Chemistry; Rogers, R.D., Seddon, K.R., Eds.; ACS Symposium Series; American Chemical Society (Oxford University Press): Washington, DC, USA, 2002; Volume 818, pp. 230-240.

17. Zhang, H.; Hong, K.; Mays, J.W. Free Radical Polymerization of Styrene and Methyl Methacrylate in Various Room Temperature Ionic Liquids. In Ionic Liquids in Polymer Systems: Solvents, additives, and novel applications; Brazel, C.S., Rogers, R.D., Eds.; ACS Symposium Series; American Chemical Society: Washington, DC, USA, 2005; Volume 913, pp. 1-15.

18. Zhao, H.; Xia, S.; Ma, P. Use of ionic liquids as 'green' solvents for extractions. J. Chem. Technol. Biotechnol. 2005, 80, 1089-1096. [CrossRef]

19. Hough, W.L.; Rogers, R.D. Ionic liquids then and now: From solvents to materials to active pharmaceutical ingredients. Bull. Chem. Soc. Jpn. 2007, 80, 2262-2269. [CrossRef]

20. Han, D.; Zhu, T.; Row, K.-H. Ultrasonic extraction of phenolic compounds from Laminaria japonica Aresch using ionic liquid as extraction solvent. Bull. Korean Chem. Soc. 2011, 32, 2212-2216. [CrossRef]

21. Ma, W.; Lu, Y.; Hu, R.; Chen, J.; Zhang, Z.; Pan, Y. Application of ionic liquids-based microwave-assisted extraction of three alkaloids N-nornuciferine, O-nornuciferine, and nuciferine from lotus leaf. Talanta 2010, 80, 1292-1297. [CrossRef]

22. Lin, H.; Zhang, Y.; Han, M.; Yang, L. Aqueous ionic liquid based ultrasonic assisted extraction of eight ginsenosides from ginseng root. Ultrason. Sonochem. 2013, 20, 680-684. [CrossRef]

23. Sun, Y.; Liu, Z.; Wang, J.; Yang, S.; Li, B.; Xu, N. Aqueous ionic liquid based ultrasonic assisted extraction of four acetophenones from the Chinese medicinal plant Cynanchum bungei Decne. Ultrason. Sonochem. 2013, 20, 180-186. [CrossRef]

24. Cao, X.; Ye, X.; Lu, Y.; Yu, Y.; Mo, W. Ionic liquid-based ultrasonic-assisted extraction of piperine from white pepper. Analytica Chimica Acta. 2009, 640, 47-51. [CrossRef] [PubMed]

25. Liu, Z.; Gu, H.; Yang, L. A novel approach for the simultaneous extraction of dihydroquercetin and arabinogalactan from Larix gmelinii by homogenate-ultrasound-synergistic technique using the ionic liquid. J. Mol. Liq. 2018, 261, 41-49. [CrossRef]

26. Tang, B.; Bi, W.; Tian, M.; Row, K.H. Application of ionic liquid for extraction and separation of bioactive compounds from plants. J. Chromatogr. B 2012, 904, 1-21. [CrossRef] [PubMed]

27. Gereniu, C.R.N.; Saravana, P.S.; Chun, B.-S. Recovery of carrageenan from Solomon Islands red seaweed using ionic liquid-assisted subcritical water extraction. Sep. Purif. Technol. 2018, 196, 309-317. [CrossRef]

28. Dai, Y.; Spronen, J.; Witkamp, G.J.; Verpoorte, R.; Choi, Y.H. Ionic liquids and deep eutectic solvents in natural products research: Mixtures of solids as extraction solvents. J. Nat. Prod. 2013, 76, 2162-2173. [CrossRef]

29. Kroon, M.C.; van Spronsen, J.; Peters, C.J.; Sheldon, R.A.; Witkamp, G.-J. Recovery of pure products from ionic liquids using supercritical carbon dioxide as a co-solvent in extractions or as an anti-solvent in precipitations. Green Chem. 2006, 8, 246-249. [CrossRef]

30. Schäfer, T.; Rodrigues, C.M.; Afonso, C.A.M.; Crespo, J.G. Selective recovery of solutes from ionic liquids by pervaporation-a novel approach for purification and green processing. Chem. Commun. 2001, 17, 1622-1623. [CrossRef]

31. Yang, X.; Wei, M.; Tian, H.; Liu, T.; Yang, L. Enrichment and Purification of Aucubin from Eucommia ulmoides Ionic Liquid Extract Using Macroporous Resins. Materials 2018, 11, 1758. [CrossRef]

32. Fan, J.; Fan, Y.; Pei, Y.; Wu, K.; Wang, J.; Fan, M. Solvent extraction of selected endocrine-disrupting phenols using ionic liquids. Sep. Purif. Technol. 2008, 61, 324-331. [CrossRef]

33. Wang, L.; Bai, M.; Qin, Y.; Liu, B.; Wang, Y.; Zhou, Y. Application of Ionic Liquid-Based Ultrasonic-Assisted Extraction of Flavonoids from Bamboo Leaves. Molecules 2018, 23, 2309. [CrossRef]

34. Tan, Z.; Yi, Y.; Wang, H.; Zhou, W.; Wang, C. Extraction, Preconcentration and Isolation of Flavonoids from Apocynum venetum L. Leaves Using Ionic Liquid-Based Ultrasonic-Assisted Extraction Coupled with an Aqueous Biphasic System. Molecules 2016, 21, 262. [CrossRef] [PubMed]

35. Trivedi, T.J.; Kumar, A. Efficient Extraction of Agarose from Red Algae Using Ionic Liquids Ionic Liquids. Green Sustainable Chem. 2014, 4, 190-201. [CrossRef] 
36. Lapkin, A.A.; Piucinski, P.K.; Cutler, M. Comparative assessment of technologies for extraction of artemisinin. J. Nat. Prod. 2006, 69, 1653-1664. [CrossRef] [PubMed]

37. Duffy, D.; Cremin, N.; Napier, M.; Robinson, S.; Barrett, M.; Hao, H.; Glennon, B. In situ monitoring, control and optimization of a liquid-liquid phase separation crystallization. Chem. Eng. Sci. 2012, 77, 112-121. [CrossRef]

38. Davey, R.; Garside, J. Form Molecules to Crystallizers: An Introduction to Crystallization; Oxford University press: New York, NY, USA, 2000; pp. 9-24.

39. Chen, J.; Sarma, B.; Evans, J.M.B.; Myerson, A.S. Pharmaceutical Crystallization. Cryst. Growth Des. 2011, 1, 887-895. [CrossRef]

40. Qu, H.; Munk, T.; Cornett, C.; Wu, J.X.; Botker, J.P.; Christensen, L.P.; Rantanen, J.; Tian, F. Influence of temperature on solvent-mediated anhydrate-to-hydrate transformation kinetics. Pharm. Res. 2011, 28, 364-373. [CrossRef]

Sample Availability: Not available.

(C) 2019 by the authors. Licensee MDPI, Basel, Switzerland. This article is an open access article distributed under the terms and conditions of the Creative Commons Attribution (CC BY) license (http://creativecommons.org/licenses/by/4.0/). 